\title{
PROJETO PADRINHOS: ACOLHIMENTO, INTEGRAÇÃO E ORIENTAÇÃO PARA OS ESTUDANTES INGRESSANTES DA ESCOLA POLITÉCNICA DA UNIVERSIDADE DE PERNAMBUCO
}

Hamilton Celerino da Fonseca Neto - hamiltonneto62@gmail.com

Escola Politécnica da Universidade de Pernambuco

Rua Benfica, 455

50.720-001 - Recife - Pernambuco

Anna Lúcia Miranda Costa - annalucia@poli.br

Escola Politécnica da Universidade de Pernambuco

Rua Benfica, 455

50.720-001 - Recife - Pernambuco

Maria Fernanda Nicéas de Albuquerque Souza - fernandaniceas@gmail.com

Escola Politécnica da Universidade de Pernambuco

Rua Benfica, 455

50.720-001 - Recife - Pernambuco

Matheus de Amorim Barros - mab@poli.br

Escola Politécnica da Universidade de Pernambuco

Rua Benfica, 455

50.720-001 - Recife - Pernambuco

Thays Marques Ferreira - thaysfmarques@gmail.com

Escola Politécnica da Universidade de Pernambuco

Rua Benfica, 455

50.720-001 - Recife - Pernambuco

Resumo: Este artigo apresenta ações promovidas pelo Projeto Padrinhos que tem o objetivo de acolher e integrar o estudante ingressante da Escola Politécnica de Pernambuco (POLI), tendo em vista o reconhecimento dos aspectos desafiadores que caracterizam a transição do Ensino Médio ao Superior. O Projeto contemplou as seguintes ações: Semana do Estudante Ingressante e a Tutoria Estudantil que buscaram, respectivamente, identificar o perfil do ingressante do periodo 2020.1 e a participação deste nas ações de acolhimento, integração e orientação ofertadas pelo Projeto Padrinhos. Como recurso metodológico foi usado um formulário do 'Google Forms' abordando 27 questões. Como resultado, apresentam-se os 
seguintes dados: 138 ingressantes 'acolhidos' do sexo masculino e 59 do feminino; quanto a rede de ensino, 139 são provenientes da rede privada e 58 da rede pública; em relação aos ingressantes 'acolhidos' que tiveram a experiência com curso técnico, dos 197, 24 concluíram e 15 cursam; observa-se ainda que, quanto a variável trabalho, dos 197 ingressantes 'acolhidos', 21 trabalham; contabiliza-se que 227 foram ingressantes acolhidos na matrícula e 166 foram acolhidos no Curso de Matemática Básica referente ao total de 266 ingressantes. Quanto as ações da Tutoria, obteve-se o resultado de 197 alunos participantes. Tais resultados fortalecem o Projeto e validam o compromisso da POLI com o bem-estar do ingressante, considerando que sua integração efetiva ao novo contexto acadêmico influencia o percurso formativo e o desempenho acadêmico.

Palavras-chave: Acolhimento. Estudantes Ingressantes. Integração. Orientação.

\section{INTRODUÇÃO}

A Escola Politécnica da Universidade de Pernambuco - POLI é uma instituição de referência brasileira nos cursos de engenharia desde 1912. É notadamente reconhecida pelo ensino de excelência que oferta e pelo alto nível acadêmico de seu corpo docente. Promove a formação em sete cursos de graduação em engenharia: Mecânica Industrial; Civil; Eletrônica; Eletrotécnica; Telecomunicações; Computação e Controle e Automação; e no curso de Física de Materiais. Comprometida com a produção da pesquisa, a POLI oferece qualificados cursos de pós-graduação em nível de lato sensu (mais de 20 cursos) e stricto sensu (02 mestrados e um doutorado) (POLI, 2018).

A busca pela manutenção da excelência do ensino também faz com que a coordenação pedagógica da POLI se preocupe com o processo de aprendizagem do estudante ingressante da graduação. Reconhece a existência de fatores relacionados ao impacto causado pela transição do Ensino Médio para o Ensino Superior que comprometem o desempenho acadêmico, como por exemplo "(...) ritmo acelerado na abordagem dos conteúdos; saída da casa dos pais; insatisfação com o curso optado; falta de um acompanhamento mais próximo por parte do corpo docente; falta de conhecimento prévio sobre as competências necessárias em um curso de engenharia e fragilidade na formação de matemática básica" (SOUZA, 2019, p. 2).

Comprometida com esta demanda, a POLI abre espaço para a criação de um equipamento social denominado Núcleo de Apoio Psicopedagógico Inclusivo - NAPSI, que assume enquanto atribuições "identificar e minimizar as lacunas que os estudantes trazem de sua formação anterior, promovendo mecanismos de nivelamento e formação" (NAPSI, 2012, p. 4). Para efetivar o compromisso assumido com o ingressante, o NAPSI criou em 2012 um projeto de extensão denominado Projeto Padrinhos que tem como objetivo: acolher, integrar e orientar academicamente estes estudantes. O Projeto se justifica porque é imprescindível 
refletir não só a respeito do acolhimento na universidade, como também sobre a influência que as ações de integração e de inclusão têm ao longo dessa nova etapa.

O Projeto Padrinhos é organizado em diferentes versões (internas e externas à comunidade POLI) e ações, todas direcionadas aos propósitos mencionados: acolhimento, integração e orientação. Para fins de produção deste artigo, duas de suas ações são apresentadas: a Semana do Estudante Ingressante (SEI) e a Tutoria Estudantil (TE). A SEI se configura como um conjunto de práticas que objetivam recepcionar e acolher o estudante no início de sua chegada ao contexto universitário. É importante salientar que essas ações mencionadas anteriormente são elaboradas, coordenadas e executadas por estudantes veteranos que integram a equipe do Projeto Padrinhos.

A Tutoria Estudantil se configura como uma ação que tem o objetivo de promover a integração efetiva do ingressante através do acompanhamento sistemático dos tutores. Escolhidos por seus pares, estudantes veteranos tornam-se tutores voluntariamente e assumem o compromisso de acompanhar academicamente a turma ingressante de seu respectivo curso, orientando o grupo nas primeiras atividades escolares. Garantem também a recepção dos ingressantes retardatários (remanejados), ajudam na integração e monitoram todo o primeiro semestre de forma a contribuir com a redução do impacto causado pela transição entre os níveis de ensino.

O exercício do protagonismo estudantil é uma das riquezas proporcionadas aos coordenadores e tutores do Projeto Padrinhos. Este protagonismo não vem só em decorrência da autonomia e do empoderamento na organização e execução das atividades, se trata do expervenviciamento das ações propostas como um todo. De acordo com Zauza (2011) 'expervivenciar' corresponde às experiências vividas. $\mathrm{O}$ termo propõe um sentido a experiência educativa. Muitas dessas experiências vividas pelos integrantes no Projeto Padrinhos, como autonomia, liderança e empatia não são abordadas normalmente nos assuntos propostos na matriz curricular das disciplinas de engenharia, o que as torna ainda mais singulares e especiais.

\section{METODOLOGIA}

Considerando a situação atual de recolhimento social em decorrência da pandemia causada pelo CODIV-19, não foi possível vivenciar integralmente as duas ações antes mencionadas: SEI e a Tutoria Estudantil. No entanto, para fins de produção deste artigo, foram resgatados dados de identificação do perfil da maioria dos ingressantes e sua respectiva participação na SEI. Através de uso de um formulário realizado na plataforma 'Google Forms', os dados foram coletados, organizados e analisados. Para a divulgação do formulário aos ingressantes, foi utilizado um aplicativo de mensagens instantâneas (canal efetivo de comunicação entre tutores e 'orientados').

A pesquisa assumiu um caráter quantitativo ao se utilizar de um formulário contendo vinte e sete perguntas objetivas e subjetivas. As questões foram organizadas em quatro categorias: de caráter pessoal; acadêmico; de avaliação da participação dos ingressantes e de nível de satisfação. 
"Os desafios para formar hoje o engenheiro do amanhã"

Quadro 1 - Categorias do formulário respondido pelos alunos ingressantes 'orientados'.

\begin{tabular}{|l|l|}
\hline 1) Pessoal & Caracteriza o aluno ingressante; \\
\hline 2) Acadêmico & $\begin{array}{l}\text { Caracteriza a "bagagem" acadêmica do aluno ingressante antes de sua } \\
\text { entrada efetiva da POLI; }\end{array}$ \\
\hline $\begin{array}{l}\text { 3) Avaliação da participação } \\
\text { dos ingressantes }\end{array}$ & $\begin{array}{l}\text { Avalia o quantitativo de participação dos ingressantes nas ações promovidas } \\
\text { pelo Projeto Padrinhos; }\end{array}$ \\
\hline 4) Satisfação dos ingressantes & Qualifica e reafirma a importância da orientação do tutor. \\
\hline
\end{tabular}

Fonte: autor (2020)

A partir das respostas ao formulário se analisou: o quantitativo de ingressantes e participantes do Projeto Padrinhos do sexo feminino e masculino; a rede de ensino do colégio de origem; se possui experiência com curso técnico; que trabalham; 'acolhidos' no ato da matrícula; participantes do Curso de Matemática Básica; 'integrados' pela Tutoria Estudantil e orientados pelo grupo através do canal de comunicação do Projeto.

\section{RESULTADOS E DISCUSSÃO}

Para não perder de vista o objetivo maior que justifica o Projeto Padrinhos, os resultados são apresentados de acordo com as finalidades da ação destacada: acolhimento, integração ou orientação.

\subsection{Perfil do ingressante}

\subsection{A Análise do perfil quanto à escola de origem e ao sexo}

Figura 1: Escola de origem x sexo.

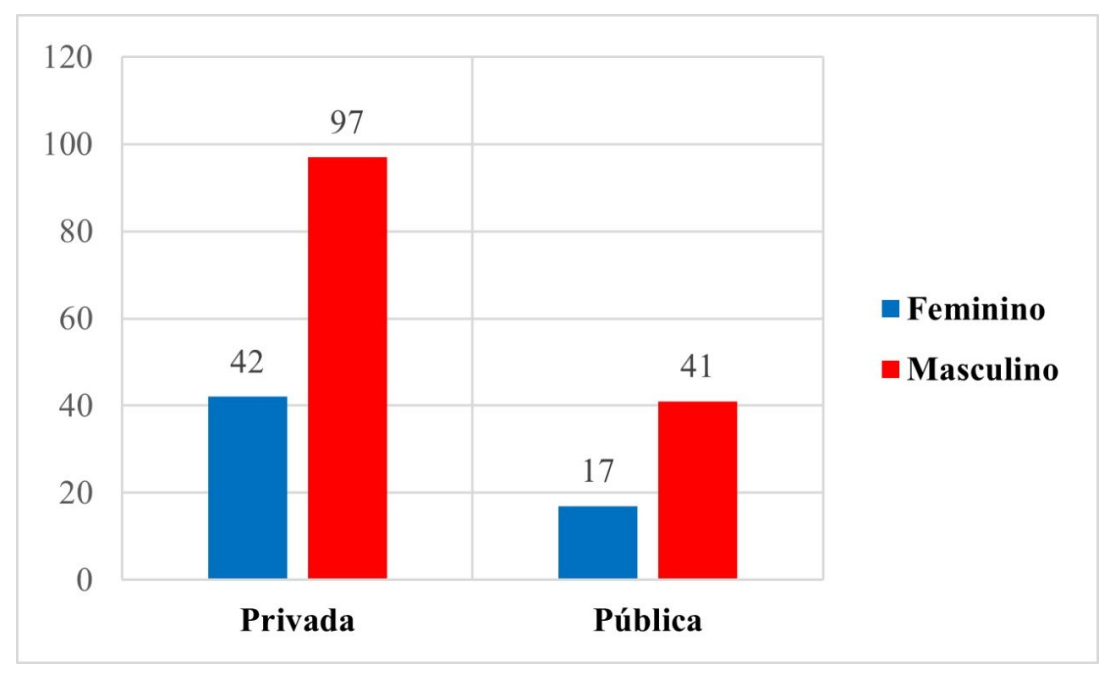

Fonte: autor (2020). 
Com base na avaliação dos dados coletados, observamos que o quantitativo, em percentual, de sexo feminino na rede privada corresponde a $21,31 \%$ do total dos ingressantes (197), enquanto na rede pública este percentual é ainda mais baixo, correspondendo a 8,62\% do total. Este resultado não surpreende considerando que se trata de um dado já observado em períodos anteriores. A literatura sobre o tema do perfil do aluno de engenharia no Brasil considera que, historicamente, há uma maior incidência do sexo masculino (NASCIMENTO, 2017). Ressalta-se, ainda, que este resultado faz referência aos estudos relacionados ao acesso à universidade, onde temáticas como igualdade de direitos e políticas afirmativas perpassam por essas discussões.

\subsection{B Análise do Perfil quanto às experiências em curso técnico e ingressantes que trabalham}

Figura 2: Experiência em curso técnico x ingressantes que trabalham.

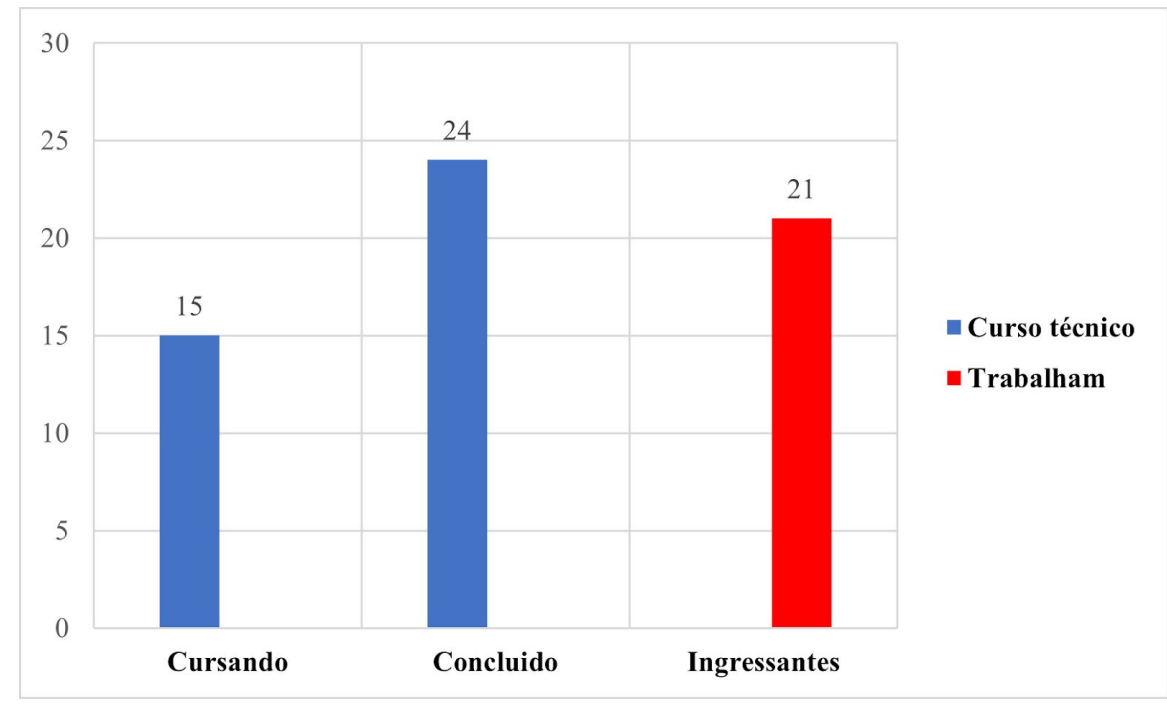

Fonte: autor (2020).

A respeito dos dados obtidos, referente a experiência com o curso técnico, observa-se que da amostra de 197 ingressantes, 24 concluíram algum curso técnico $(12,18 \%)$ e 15 conciliam este curso com a graduação $(7,61 \%)$. Os resultados dos últimos períodos referentes a este indicador apontam uma crescente no número de ingressantes que iniciam o curso universitário ou como também aluno de um curso técnico ou como egresso do mesmo. Supondo que esta experiência mantém uma relação direta com o desempenho acadêmico do ingressante, uma grupo de tutores do NAPSI está desenvolvendo uma pesquisa para investigar essa hipótese.

Levando em consideração os dados referentes aos ingressantes que trabalham, obteve-se o percentual de $10,66 \%$ a respeito do total de 197 alunos 'orientados'. Se faz necessário pontuar que tal atividade, exercida por um número razoável de alunos, implica em uma menor 


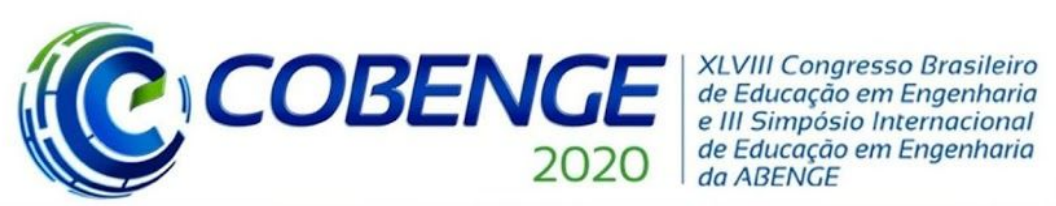

"Os desafios para formar hoje o engenheiro do amanhã"
O1 a 03 de dezembro Evento On-line

disponibilidade de tempo em exercer as práticas extracurriculares propostas pela Universidade.

\subsection{Semana do Estudante Ingressante}

\section{2. $A$ Ingressantes 'acolhidos' no ato da matrícula}

Figura 3: Ingressantes acolhidos no ato da matrícula.

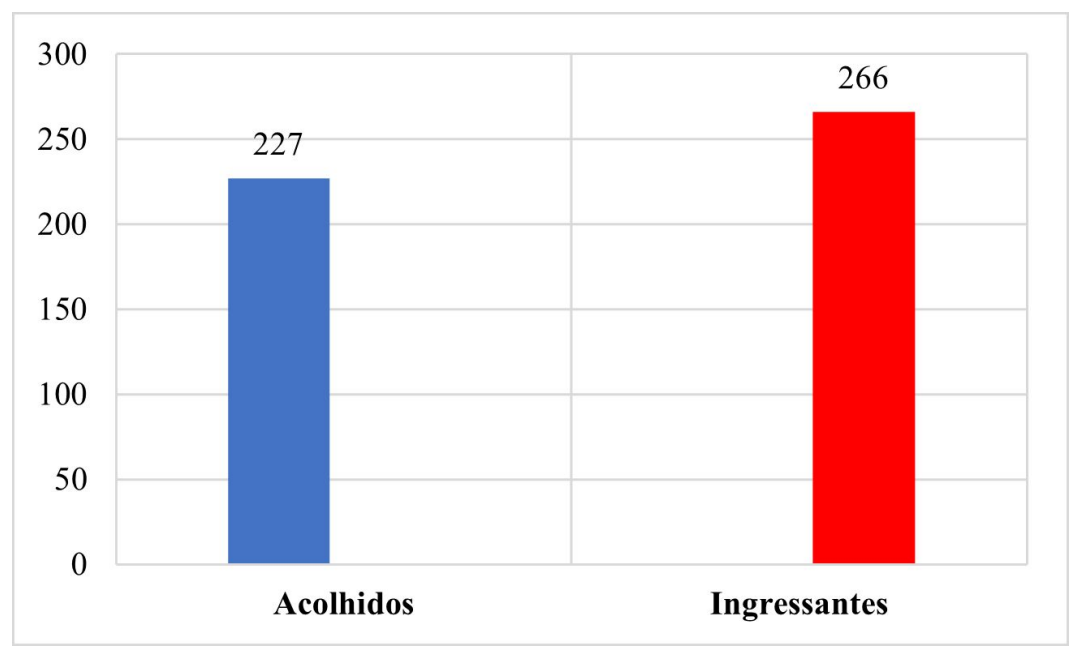

Fonte: autor (2020).

A Figura 3 mostra a relação entre o quantitativo de alunos acolhidos no ato da matrícula regular (sem remanejamento) e os alunos ingressantes no período de 2020.1. A partir desses dados, a coordenação do Projeto Padrinhos nota e registra a importância e abrangência da ação quando constata que foram acolhidos 85,34\% ingressantes do período de 2020.1 da POLI.

Devido aos remanejamentos ocorrerem após o início do semestre e da matrícula regular, esta ação de acolhimento promovida ao longo dos meses de janeiro e fevereiro não registra $100 \%$ de acolhimento aos alunos ingressantes, afinal a divulgação dos nomes e a matrícula dos estudantes remanejados ocorreram depois do acolhimento feito na matrícula regular.

\subsection{B Ingressantes 'acolhidos' no Curso de Matemática Básica}

Figura 4: Ingressantes acolhidos no Curso Matemática Básica (CMB). 


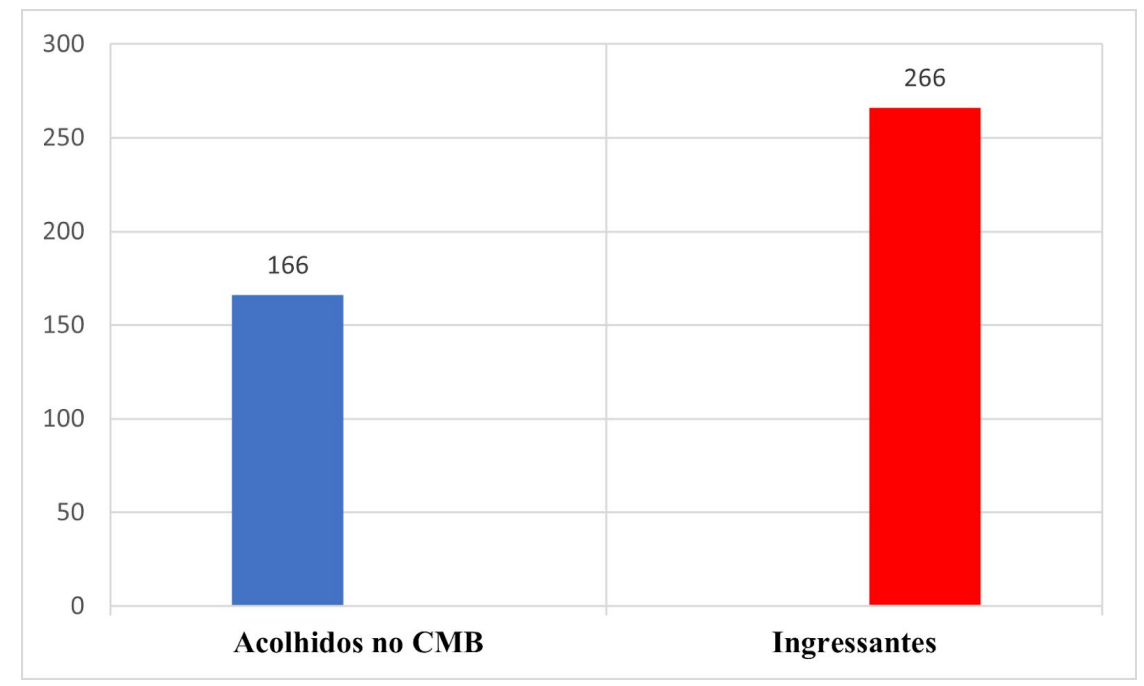

Fonte: autor (2020).

Através da coleta destes dados, pudemos concluir que do percentual total, $62,40 \%$ dos alunos participaram dessa prática. Dentre diversas razões para que o percentual registrado não tenha o alcance de $100 \%$ dos ingressantes, citamos como por exemplos: alunos que trabalham ou que fazem curso técnico no contra turno referente aos seus cursos, momento esse em que é realizado o Curso de Matemática Básica; alunos que moram em cidades mais afastadas do Recife e utilizam os ônibus ofertados pela prefeitura, que possuem horário marcado; ou até mesmo por falta de estímulo por parte dos alunos que já cursaram alguma graduação na área de exatas.

Para garantir que estes estudantes sejam acolhidos no Curso de Matemática Básica, os monitores, alunos veteranos, além de auxiliarem nos assuntos referentes às disciplinas de Cálculo e Geometria Analítica, apresentam e esclarecem as atividades ofertadas pela POLI, ressaltando a importância da realização delas em um ambiente universitário, além de compartilhar parte de suas experiências e vivências em uma universidade alicerçada na tríade: ensino, pesquisa e extensão.

\subsection{Ingressantes acompanhados através da TE e orientados pelos canais de comunicação}

Figura 5: Ingressantes acompanhados x orientados. 
(C) COBENGE

"Os desafios para formar hoje o engenheiro do amanhã"

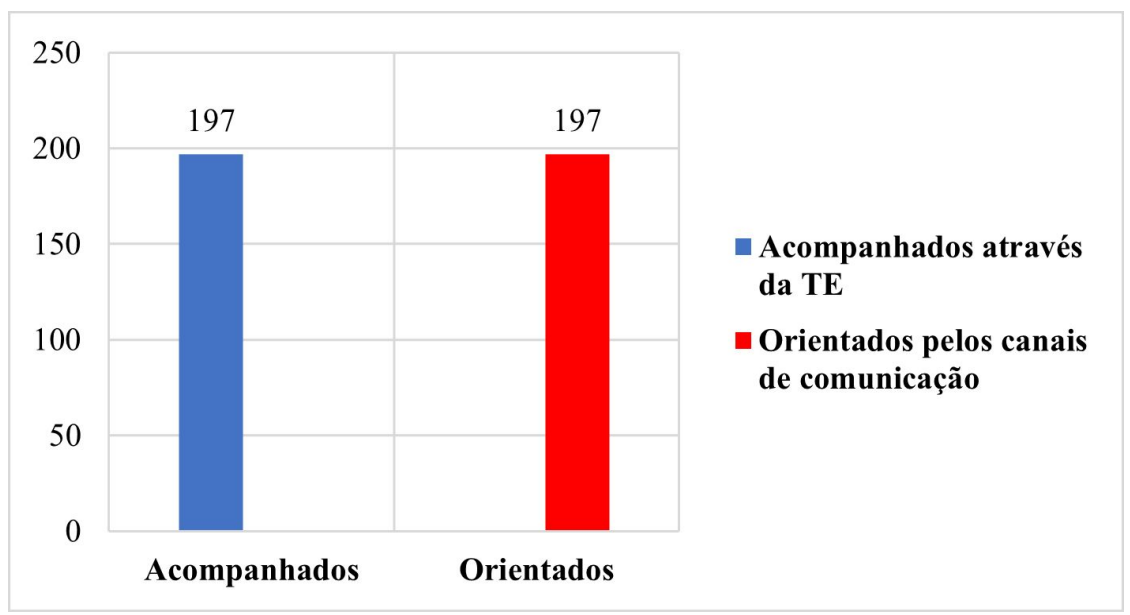

Fonte: autor (2020).

No que diz respeito a Figura 5, ao compararmos o quantitativo de alunos ingressantes no período 2020.1 com o quantitativo de alunos acompanhados pela Tutoria Estudantil, podemos afirmar que um percentual de $74,06 \%$ do total dos ingressantes (266) participaram do acompanhamento oferecido pelo Projeto. Os 25,94\% restantes optaram por não serem acompanhados devido a diversos fatores, sendo o principal a experiência de haver frequentado ambientes universitários ou técnicos anteriormente, e consequentemente vivenciado o processo de transição acadêmica.

Em relação aos orientados através dos nossos canais de comunicação, percebemos que o total de alunos, até o momento da coleta dos dados, corresponde a $100 \%$ do total de alunos integrados através do acompanhamento desenvolvido pela TE. Dessa forma, concluímos que todos os alunos que foram acolhidos pelo Projeto Padrinhos também for orientados pelas equipes de tutoria e coordenação.

\section{CONSIDERAÇÕES FINAIS}

O Projeto Padrinhos, alicerçado nos pilares de acolhimento, integração e orientação, tem buscado incessantemente estratégias, ações e ferramentas que possibilitem o enfrentamento aos desafios provocados pela transição do Ensino Médio para o Superior. As pesquisas, análises e as avaliações do Projeto proporcionam o conhecimento referente aos ingressantes que são repassadas aos coordenadores de curso, a fim de traçarem estratégias e práticas pedagógicas que efetivamente atendam às necessidades de aprendizagens. A coordenação do Projeto observa que estas ações influenciam na redução do índice de retenção e evasão observados no primeiro ano.

Quanto aos resultados identificados neste artigo, foram positivamente avaliados pela coordenação e comemorados como decorrente de uma evolução do Projeto, pois em todas as práticas têm-se os resultados de mais de $60 \%$ de participação dos ingressantes do período de 2020.1. Ressalta-se que a coordenação identifica algumas limitações perante o comparativo feito entre os resultados obtidos e desejados, visto que buscamos promover o acolhimento dos 
(C) COBENGE

"Os desafios para formar hoje o engenheiro do amanhã"
O1 a 03 de dezembro Evento On-line

alunos em sua totalidade (100\%) e obtivemos uma média percentual de $82,95 \%$ de alunos acolhidos. Tornam-se, ainda, imprescindíveis as melhorias das ferramentas de análises e obtenção de dados para uma execução mais eficiente do Projeto, bem como a busca por novas metodologias pedagógicas que auxiliem o ingressante a superar os desafios característicos da transição acadêmica.

\section{AGRADECIMENTOS}

Dedicamos esta parte do trabalho para registrar os nossos mais sinceros sentimentos de gratidão aos que fizeram e fazem este Projeto acontecer, desde os alunos ingressantes, que acreditaram na nossa proposta que o fizeram conosco, como também a todos os alunos tutores, a coordenação da Tutoria Estudantil, aos coordenadores do NAPSI, e em especial a nossa coordenadora e pedagoga. Agradecemos também ao diretor da POLI, José Roberto de Souza Cavalcanti, e aos coordenadores que acreditam, apostam e apoiam o Projeto Padrinhos.

\section{REFERÊNCIAS}

ESCOLA POLITÉCNICA DE PERNAMBUCO (POLI). Regimento Interno do Núcleo de Apoio Psicopedagógico Inclusivo (NAPSI). Conselho Gestor Acadêmico.12 de jun. 2012. p. 4.

ESCOLA POLITÉCNICA DA UNIVERSIDADE DE PERNAMBUCO (POLI). Relatório de Atividades da Gestão 2014 - 2018, 2018. p. 5. Disponível em:

http://upe.poli.br/relatorios-de-atividades/. Acesso em: 20 mai. 2020.

\section{NASCIMENTO, Jaqueline D. D. MULHERES NOS CURSOS DE ENGENHARIA DA}

UFBA: um estudo sobre o acesso e desempenho. 2017, 269 f. Tese (Doutorado em Educação) - Faculdade de Educação da Universidade Federal da Bahia, 2017. Disponível em: https://repositorio.ufba.br/ri/handle/ri/24257 . Acesso em: 24 set. 2020.

SOUZA, Maria F. N. D. A. et al. PROJETO PADRINHOS DA POLI/UPE: ESTRATÉGIA DE APROXIMAÇÃO ENTRE O ENSINO MÉDIO E O ENSINO SUPERIOR. XLVII Congresso Brasileiro de Educação em Engenharia, 2019, Ceará. Anais. Fortaleza, 2019. Disponível em http://www.abenge.org.br/cobenge/2019/anais.php. Acesso em: 11 mai.2020.

ZAUZA, G. V. Para quem sofre. Poesia. Revista da Academia Passo-fundense de Letras, Passo Fundo, n. 7, 8, 9, maio 2011. Disponível em:

https://www.researchgate.net/publication/321812043_Educacao_estetica_e imaginario numa jornada_arquetipica. Acesso em: 11 mai. 2020. 


\title{
PROJETO PADRINHOS: RECEPTION, INTEGRATION AND ORIENTATION FOR THE INCOMING STUDENTS OF ESCOLA POLITÉCNICA DA UNIVERSIDADE DE PERNAMBUCO
}

\begin{abstract}
This article presents the development of actions promoted by Projeto Padrinhos, which aims to welcome and integrate the entrant student from Escola Politécnica de Pernambuco (POLI), in order to recognize the challenging aspects that characterize this transition from High School to College. The Project contemplates the following actions: Semanas dos Estudantes Ingressantes and Tutoria Estudantil, that aims, respectively, to identify the profile of the 2020.1 entrants and their participation in the reception, integration and orientation actions offered by the Projeto Padrinhos. As a methodological resource, the 'Google Forms' platform was used to allocate 27 questions. As a result, the following numbers that were collected were: 138 male and 59 female 'welcome' entrants; as for the educational system, 139 come from the private system and 58 from the public system; as for the 'welcome' entrants who had experience in the technical course, of the 197, 24 concluded, 15 are still attending; it is also observed that as for the work variable, of the 197 'welcome' entrants, 21 work; we also calculate that 227 were welcome entrants at registration and 166 were welcome in the Curso de Matemática Básica referring to the total of 266 entrants. About the Tutoring actions, the results of 197 participating students were obtained. These results strengthen the Project and validate POLI's commitment to the well-being of the entrant, considering that its effective integration to the new academic context influences the educational path and academic performance.
\end{abstract}

Keyword: Reception. Incoming Students. Integration. Orientation. 